\title{
Teoria e prática: as experiências formadoras da docência
}

\author{
Juliana Brandão Machado, FACED - UFRGS \\ profjulianamachado@gmail.com \\ Marie Jane Soares Carvalho, FACED - UFRGS \\ marie.jane@ufrgs.br
}

Resumo: O presente artigo analisa as experiências formadoras da docência a partir das reflexões pautadas pela relação entre teoria e prática na trajetória formativa das professoras-cursistas do curso de Graduação em Pedagogia na Modalidade a Distância, oferecido pela Universidade Federal do Rio Grande do Sul (PEAD/UFRGS), entre os anos de 2006 e 2010, no âmbito da cibersocialidade. Experiência formadora constitui-se como a possibilidade de criar e recriar, no âmbito da formação, as significações a respeito do aprendido: aprendido a fazer, a ser e a pensar. A cibersocialidade se relaciona à vivência do cotidiano presentificado, em que emergem as relações na sociedade em rede. As experiências formadoras foram analisadas a partir dos Portfólios de Aprendizagem das professoras-cursistas, recuperando as recordações-referência a partir dos seus itinerários de experiências individuais. Percebemos que estas se relacionam necessariamente com o mundo da vida cotidiana de cada professora-cursista, ultrapassando as fronteiras da universidade e da escola. Destacamos a importância de assumirmos a experiência formadora como possibilidade de qualificar a formação de professores.

Palavras-chave: Experiência Formadora; Formação de Professores; Educação a Distância.

\section{Theory and practice: the formative experiences of teaching}

\begin{abstract}
This article examines the formative experiences of teaching from the reflections guided by the relationship between theory and practice in the trajectory of the teachers - participants Course Undergraduate Education in Distance mode , offered by the Federal University of Rio Grande do Sul, between the years 2006-2010, under the cibersocialidade. Experience is shaping up as the ability to create and recreate, in training, about the meanings learned: learned to do, to be and to think. The cibersocialidade relates to everyday living -present in the relationships that emerge in the network society. The formative experiences were analyzed from the Portfolios of the teachers-learning course participants, recovering memories-reference from their itineraries individual experiences. We realize that these are necessarily related to the world of everyday life of each teacher, pushing the boundaries of the university and the school. We emphasize the importance of the formative experience we assume a possibility of qualifying teacher training.
\end{abstract}

Keywords: Formative Experience, Teacher Training, Distance Education. 


\section{Contextualizando a pesquisa}

A reflexão que se apresenta neste artigo é parte de um estudo mais abrangente, cujo resultado foi apresentado em uma tese de doutorado a respeito das experiências formadoras da docência. Tal tese analisou o mundo da vida cotidiana de professorescursistas em sua trajetória formativa no curso PEAD/UFRGS. Ao longo dessa análise observou-se que um dos elementos mais significativos na trajetória de formação destes sujeitos foi a aproximação entre teoria e prática. Em consequência disso, apresentaremos a discussão sobre essa relação na trajetória formativa de professores, com o intuito de avançar nas discussões sobre a formação de professores no âmbito da aproximação entre a abordagem teórico-conceitual e a prática pedagógica.

O fundamento para essa análise é o conceito de experiência formadora, que recupera o sentido integral da formação docente, na perspectiva de aproximar o saber ao saber-fazer. Apresentaremos, em linhas gerais, o conceito de experiências formadoras, como fundamento conceitual dessa análise. Em seguida, será recuperado o percurso metodológico de abordagem dos dados, que resultou numa análise das experiências formadoras da docência que se relacionam à aproximação entre teoria e prática. Por fim, as considerações finais pretendem apontar elementos que se relacionem à importância de assumirmos a experiência formadora como possibilidade de qualificar a formação de professores.

\section{Experiência Formadora: um conceito balizador}

O conceito de experiência formadora foi desenvolvido por Marie-Christine Josso (2004). A autora desenvolve um método de pesquisa particular para conceituar a formação através da experiência. A abordagem biográfica da formação do sujeito consiste em enfatizar o processo de formação do ponto de vista daquele que aprende e seu processo de aprendizagem (JOSSO, 2004).

A ênfase da autora na ideia da experiência como formadora está embasada na perspectiva de compreensão de que os processos de formação do sujeito estão em consolidação ao longo de sua trajetória de vida. Nesse sentido, a perspectiva biográfica consolida a análise das experiências de formação. Do ponto de vista do pesquisador,

A problemática da experiência conduz a uma reflexão sobre as modalidades de elaboração dos saberes, de compreensão e de explicação dos fenômenos que o pesquisador adotou como objeto de pesquisa. Este tema, como o da intersubjetividade, permite interrogar-se a respeito das condições de possibilidades do processo de conhecimento[...]. (JOSSO, 2010, p.111)

Para Josso (2004) as histórias de vida devem ser abordadas como um projeto de conhecimento e de formação, salientando as relações do sujeito aprendente com o saber. Por isso, ao denominar o sujeito em formação, a autora utiliza o termo aprendente, para denotar o ponto de vista do sujeito que está aprendendo e atribuir um caráter dinâmico (em processo) a esse movimento.

Ao conceituar experiência, a autora destaca:

a experiência pode tornar-se em tal a posteriori de um acontecimento, de uma situação, de uma interação; é o trabalho de reflexão sobre o que se passou; mas uma atividade qualquer é também experiência desde que o sujeito se conceda os meios de observar, no decorrer da atividade, o que se passa e reflita sobre o que esta observação lhe traz como informação sobre a atividade empreendida. Em outras palavras, uma experiência é uma ação refletida a priori ou a posteriori. (JOSSO, 2004, p.143) 
Assim, a experiência inclui a reflexão, ou seja, o processo da consciência pelo qual o sujeito passa para transformar o vivido em experiência é tomado pelos mecanismos que os colocam a pensar a respeito do que foi vivenciado. Josso filia sua perspectiva teórica à análise das histórias de vida, e estas têm como ponto de análise os projetos de conhecimento dos sujeitos. Nesse momento encontra-se a ideia de que é nas histórias de vida que se desenvolvem os itinerários de experiências individuais e é através dessa ideia que se forjam as experiências formadoras. O que torna uma experiência formadora, nas palavras da autora:

...é uma aprendizagem que articula, hierarquicamente: saber-fazer e conhecimentos, funcionalidade e significação, técnicas e valores num espaço-tempo que oferece a cada um a oportunidade de uma presença para si e para a situação, por meio da mobilização de uma pluralidade de registros. (JOSSO, 2004, p.39)

Formar, na perspectiva de Josso, é integrar-se numa prática o saber-fazer e os conhecimentos (idem, p.39). Nesse sentido, a formação é constituidora da inter-relação entre processo de ação e significação, estabelecendo a partir do vivido e pensado a atribuição de formadora em sua caracterização. Ao perguntar aos sujeitos $O$ que aconteceu para eu ter as ideias que hoje tenho?, a autora estabelece as linhas que definem a pesquisa-formação, em que busca reconstruir a rede de acontecimentos que levam o sujeito à formação. Nesse sentido, a intersubjetividade aparece como ponto forte na teorização de Josso. A ideia é que a subjetividade se organiza a partir da intersubjetividade, permitindo abertura à experiência que designa a dimensão transformadora do sujeito que se conhece pela produção de conhecimento (Idem, p.228). Então, a experiência formadora, consolidada na interação entre os sujeitos constrói, também, identidade, fortalecendo a singularidade no processo de desenvolvimento de cada pessoa.

Aprender pela experiência está relacionado ao movimento de resolução de problemas. Essas ideias entram diretamente em relação com a abordagem do curso PEAD/UFRGS. Ao tratarmos do contexto de professoras que atuavam profissionalmente sem uma formação em nível superior, temos que a experiência de trabalho se consolida na resolução de problemas concretos na sua atividade docente. Nesse sentido, o conceito de experiência formadora pode contribuir para o processo de compreensão de como a docência é constituída na vida dessas professoras-cursistas. Assim, a definição de Josso a respeito das experiências formadoras é pontual e emblemática:

A experiência, as experiências de vida de um indivíduo são formadoras na medida em que, a priori ou a posteriori, é possível explicitar o que foi aprendido (iniciar, integrar, subordinar), em termos de capacidade, de saberfazer, de saber pensar e de saber situar-se. O ponto de referência das aquisições experienciais redimensionam o lugar e a importância dos percursos educativos certificados na formação do aprendente, ao valorizarem um conjunto de atividades, de situações, de relações, de acontecimentos como contextos formadores. (JOSSO, 2004, p.235)

Ao longo do estudo da obra de Josso, fica a pergunta: como acessar as experiências formadoras? É possível “encontrá-las”? Para tanto, Josso inclui na sistematização de sua obra a ideia de "recordações-referência":

A recordação-referência pode ser qualificada de experiência formadora, porque o que foi aprendido (saber-fazer e conhecimentos) serve, daí para a 
frente, quer de referência a numerosíssimas situações do gênero, quer de acontecimento existencial único e decisivo na simbólica orientadora de uma vida. São as experiências que podemos utilizar como ilustração numa história para descrever uma transformação, um estado de coisas, um complexo afetivo, uma ideia, como também uma situação, um acontecimento, uma atividade ou um encontro. (JOSSO, 2004, p.40)

As recordações-referências, presentes nas narrativas de formação dos sujeitos, informam o que se aprendeu com a experiência. Nesse sentindo, o movimento é de significação pelo próprio sujeito que vivencia, seleciona e pode fazer uso em outro momento desse "aprendido". Por fim, cabe destacar que "experiência formadora” é um conceito em construção, como afirma Josso (2004, p. 48), e que pretende indicar uma articulação conscientemente elaborada entre atividade, sensibilidade, afetividade e ideação. Articulação que se objetiva numa representação e numa competência.

Reconhecendo que a docência é uma profissão de relações humanas e se constrói a partir da experiência, é fundamental estabelecer o conceito que seguirá no estudo como balizador da análise. A experiência, considerada formadora, se desenvolve na situação biográfica de cada sujeito que constrói sua formação e articula sua profissionalização. Experiência formadora constitui-se como a possibilidade de criar e recriar, no âmbito da formação, as significações a respeito do aprendido: aprendido a fazer, a ser e a pensar. O espaço da formação, que ultrapassa a delimitação de uma instituição de ensino, é o mundo da vida cotidiana, que se apresenta à interpretação dos sujeitos cotidianamente. Portanto, considerar as experiências formadoras implica reconhecer quais situações, a partir da reflexão retrospectiva do sujeito, consolidam esquemas de pensamento e sentidos a respeito do mundo, ou o estoque de conhecimento à mão.

Demarcando o contexto deste estudo, a formação na modalidade EAD incorpora ao mundo da vida cotidiana as relações estabelecidas no ciberespaço, em que se compreende uma forma de relação própria e peculiar a essa realidade: a cibersocialidade. A concepção de mundo da vida, como aquele que se apresenta à nossa experiência e interpretação pode ser ampliada na medida em que se estabelecem novas interações na sociedade em rede. $\mathrm{O}$ mundo da vida cotidiana é um mundo intersubjetivo, e esta é uma condição fundamental para o estabelecimento da cibersocialidade. As experiências vivenciadas no mundo da vida constituirão o próprio mundo, na medida em que os sujeitos interagem e o interpretam e poderão ser consideradas formadoras na medida em que sintetizam atitudes, comportamentos, pensamentos que caracterizam sua identidade.

\section{Desenho metodológico do estudo}

A análise das experiências formadoras da docência foi realizada numa forte imersão nos Portfólios de Aprendizagens das professoras-cursistas ao longo de sua formação no curso PEAD/UFRGS. O Portfólio de Aprendizagens foi uma proposta desenvolvida pelo Seminário Integrador do curso PEAD/UFRGS, a partir do Eixo 3, com o intuito de registrar as reflexões individuais de cada cursista ao longo de sua formação. Cada professor-cursista criou um blog, onde semanalmente realizava uma postagem de alguma ideia, prática, reflexão suscitada pelas experiências vividas. A proposta do Portfólio acompanhou o curso até o final e, por isso, esse instrumento foi escolhido para contemplar a trajetória de formação dos professores-cursistas. Além disso, o Portfólio teve, ao longo do curso, um aspecto menos formal diante das propostas: cada um pode 
escolher a sua apresentação, desde o layout do blog até o conteúdo da maioria das postagens.

De acordo com o pressuposto de Josso (2004), de que as experiências formadoras se vinculam às recordações-referências dessas experiências, o objetivo deste estudo foi realizar uma análise minuciosa dos registros reflexivos das professorascursistas selecionadas para participar do estudo.

Para sistematizar essa investigação, partimos do conceito de experiências formadoras definido por Josso (2004) e estabelecemos alguns percursos de análise. Nas palavras da autora, o processo de formação acentua o inventário dos recursos experienciais acumulados e das transformações identitárias (2004, p.43). Com isso, a investigação foi pautada pela busca destas experiências inventariadas pelos sujeitos, analisando, inclusive, o caráter de transformação da identidade de cada docente em questão.

A análise do conceito de experiências formadoras levou ao desenvolvimento de três procedimentos de pesquisa:

1. Apresentar os itinerários de experiências individuais de cada professora-cursista que encerra uma "síntese de reconhecimento" de uma rotina típica ou atípica do mundo da vida deste grupo. Os itinerários de experiências individuais foram "desenhados” através da seleção das experiências que, ao longo da formação no curso PEAD/UFRGS, cada professora-cursista considerou significativa para o registro em seu Portfólio de Aprendizagens. Buscamos delinear, ano a ano (de 2007 a 2010) as vivências destacadas pelas professoras, as reflexões que se relacionam ao curso, as mudanças de postura em sua sala de aula.

2. Destacar as recordações-referências que foram, ao longo do curso, enfatizadas nos registros de reflexão das professoras-estudantes. O que foi reconhecido como significativo pelas professoras-estudantes em seus registros? As recordaçõesreferências foram destacadas como as experiências que constituem o que Schütz chamou de estoque de conhecimento à mão, ou seja, situações vividas que serviram de referência e interpretação para outras vivências e foram ativadas em outras situações, sejam elas reflexivas ou de prática pedagógica.

3. Discutir os contextos de interações e de transações, que podem ser compreendidos como os aspectos que englobam o contexto de produção das experiências formadoras, e não se vinculam estritamente à formação acadêmica. Nesse momento, recupera-se a ideia de cibersocialidade, retomando o enfoque de que as experiências e vivências dos sujeitos emergem num contexto de cibercultura e são "atravessadas" pelas relações com o tempo e o espaço, e constitui-se no conceito articulador entre o mundo da vida cotidiana e as experiências formadoras.

A partir destes procedimentos a pesquisa consistiu na captura de cada Portfólio de Aprendizagem para a análise das postagens através do software QSR NVivo 10, software de análise qualitativa de dados, que permite analisar documentos de texto, construindo categorias para categorizar os dados. Inicialmente, uma leitura atenta de todas as postagens foi realizada. Diante das trajetórias formativas analisadas, a relação entre teoria e prática foi a mais destacada pelas professoras-cursistas em seu percurso formativo. Portanto, analisaremos a seguir essa relação em detalhe.

\section{As relações entre teoria e prática no processo formativo}

Ao selecionar um recorte de análise - as reflexões que aproximam a formação no curso PEAD/UFRGS (âmbito dos aspectos teóricos) à prática pedagógica de cada professoracursista, alguns registros reflexivos foram destacados na trajetória formativa destes 
docentes, constituindo suas experiências formadoras na perspectiva da relação entre teoria e prática. Iniciamos com a professora-cursista RW, com uma postagem em seu portfólio referente ao ano de 2007.

\section{IMPORTANTE É BRINCAR}

Novamente com a aula presencial vimos como é importate brincar e saber como se brinca.

Lendo os textos de Tânia Fortuna onde esclarece que o brincar nas séries iniciais é

fundamental para a criança desenvolver o seu comportamento e representar a realidade por meios de fantasias, usando brinquedos e jogos.

Nesta aula tivemos a oportunidade em criar brinquedos de sucatas, ter sugestões de colegas e ver várias produções de brinquedos confeccionados e também como se brinca. Isto servirá para as minhas aulas com os meus alunos.

POSTADO POR PORTFÓLIO DE APRENDIZAGENS MARCADORES: LUDICIDADE

Às 12:43 NENHUM COMENTÁRIO:

Figura 01 - Portfólio de Aprendizagens de RW, postagem de 18/12/2007.

RW situa o alcance das experiências formadoras no ano de 2007 na aplicação em sala de aula dos conteúdos aprendidos na graduação. Como início dos registros reflexivos em seu portfólio, esse é o destaque que a professora-cursista atribui ao seu processo formativo: extensão das aprendizagens formais do curso de graduação ao trabalho pedagógico desenvolvido em sua sala de aula. $\mathrm{O}$ primeiro ponto reflexivo na trajetória de RW foi estabelecer relações entre teoria e prática. Aqui, percebe-se que a teoria confirma e amplia a prática pedagógica.

Outro destaque é dado pela professora-cursista SB, no ano de 2009, aproximando conceitos estudados em uma Interdisciplina e sua atuação profissional.

A Figura 02 apresenta uma postagem em que a professora-cursista reflete sobre uma leitura do filósofo Theodor Adorno, buscando elementos para associá-la ao seu “estoque de conhecimentos”. Nesse exercício, SB aponta o processo de discussão que estabelece em seu trabalho em sala de aula, proporcionando aos alunos espaço para o exercício da reflexão e debate: No meu trabalho em sala de aula sempre proporciono momentos de reflexão, discussão e debate, incentivando-os a expressar seus sentimentos e ouvir os sentimentos dos outros [...]. Para a professora-cursista, este processo traz avanço na compreensão da importância do diálogo nas relações humanas. 


\section{Educação, Civilização e Barbárie}

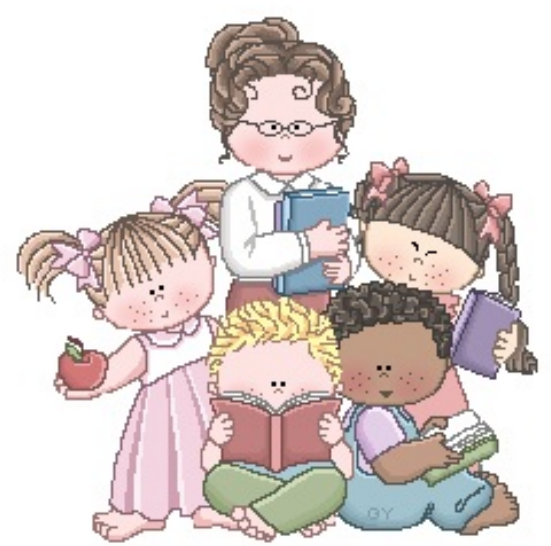

Após a leitura do texto "Educação após Auschwitz" do filósofo alemão Theodor Adorno, podemos perceber a preocupação do autor em evitar que Auschwitz se repita e deixa claro a importância da educação no processo de conscientização das pessoas em expressar afeto, respeitar e posicionar-se frente a diferentes situações da sua vida.

A barbárie que ocorreu em Auschwitz demonstra a indiferença e a frieza de pessoas autoritárias com relação aos seus semelhantes, humilhando-os, aterrorizando-os, numa violência incontrolável, tornando assim, uma civilização oprimida e estruturada em dimensões destrutivas.

Conforme o texto, Adorno afirma que "Aquele que é duro contra si mesmo adquiri o direito de sê-lo contra os

demais e se vinga da dor que não teve a liberdade de demonstrar, que precisou reprimir".

São importantes os vínculos de afeto, pois ele compreende as atitudes das pessoas diante das experiências de vida, promove impulsos e emoções diferentes, influenciando o pensamento e a conduta das pessoas.

Sabemos que não é somente resgatar sentimentos fraternos entre as pessoas, mas também o conhecimento e a reflexão sobre si mesmo. Segundo o autor, "A educação só teria pleno sentido como educação para a auto-reflexão e crítica".

A educação é fator primordial na vida do ser humano, principalmente na educação infantil, na primeira infância, na qual ela deverá proporcionar ambientes de afeto, carinho, de reflexão, autoconhecimento, compreensão da realidade social, formando cidadãos críticos e participativos. Segundo o autor Adorno "Crê-se que o quanto mais bem forem tratadas as crianças, quanto menos forem negadas na infância, mais chances elas terão".

\section{No meu trabalho, em sala de aula, sempre proporciono momentos de reflexão, discussão e debate, incentivando-os a expressar seus sentimentos e ouvir os sentimentos dos outros, mostrando assim, o valor desta ação. \\ Mesmo assim, já tivemos momentos dificeis, com alunos agredindo fisicamente e verbalmente os outros, mas o diálogo é fundamental para resolver os conflitos existentes no dia-a-dia.}

Figura 02 - Portfólio de Aprendizagens de SB, postagem de 06/06/2009.

A postagem apresenta um elemento que já foi apontado na análise da trajetória de RW: a busca pela relação entre teoria e prática. Embora com menos ênfase que no caso anterior, a professora-cursista procura demonstrar, ao longo de sua postagem, um estreitamento entre os estudos realizados nas interdisciplinas e a sua prática profissional. Por vezes parecendo meio "forçado", com pouca fluidez entre os conceitos e as práticas que deseja relacionar, o estabelecimento dessas conexões é significativo no processo de formação. Ocorre, assim, o exercício da meta-reflexão, do pensar sobre o seu fazer, buscando elementos que corroborem, justifiquem e, ainda, fortaleçam as práticas pedagógicas já construídas. 


\section{QUARTA-FEIRA, 3 DE JUNHO DE 2009}

Questões Étnico Raciais na Educação

Reflexão Teórica sobre a Prática

As tensas relações entre brancos e negros fazem parte do universo das escolas e inúmeras vezes são simuladas como harmoniosas ou tratadas como singulares e normais pelos profissionais da educação. As atitudes, idéias e intenções do aluno negro, envolvido em situações de discriminação e racismo, podem ser algumas vezes, julgadas negativamente, antes mesmo de ele se manifestar ou tomar qualquer iniciativa considerada equivocada pelos não negros. Essa situação torna imprescindível o debate sobre as dimensões das relações raciais na escola e um redimensionamento das políticas públicas de reconhecimento, valorização e respeito ao povo negro, daí a importância de se tratar do tema desde a educação infantil e séries iniciais. Diante do exposto, e de acordo com a Interdisciplina Questões Étnico-Raciais na Educação é que desenvolvi trabalhar dentro desse tema. Valorização e respeito às diferenças. Escolhi o texto de Luciane Andréia Ribeiro Leite, Era uma vez uma menina muito bonita, uma vez que vem ao encontro com a História Menina bonita do Laço de Fita. Após contar a história e trazer para a sala de aula uma menina negra e parecida com a menina bonita estudante da escola e que também conversou com eles sobre sua ancestralidade é que passaram a compreender as diferenças, embora não tivessem demonstrado nenhum tipo de preconceito ou discriminação.Comecei a perceber que o meu trabalho estava dando resultados depois de tanto insistir sobre esse assunto. Penso que o aluno reconhecendo a sua origem e percebendo as diferenças que compõe cada grupo familiar e de convivência irão aceitar o outro sem discriminar.

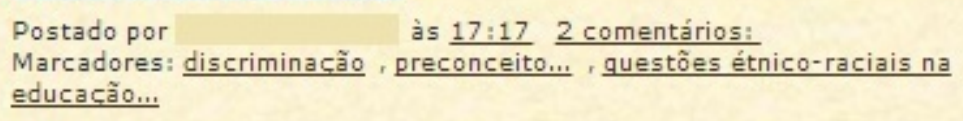

Figura 03 - Portfólio de Aprendizagens de MB, postagem de 03/06/2009.

Na postagem destacada da Figura 03, MB apresenta uma reflexão intitulada Reflexão Teórica sobre a Prática. A partir do estudo promovido na interdisciplina "Questões Étnico-Raciais na Educação: Sociologia e História”, a respeito da ancestralidade e discriminação, na temática "Valorização e respeito às diferenças", a professora-cursista realiza uma atividade em sua sala de aula que pretende discutir essa temática com seus alunos, partindo de uma história infantil e do contato com uma pessoa negra que possa conversar com as crianças. Assim, MB pretende mostrar que é importante discutir conceitos com os alunos e "persistir" nesse trabalho para obter resultados: Comecei a perceber que o meu trabalho estava dando resultado depois de tanto insistir sobre esse assunto. Para fins dessa análise, importa destacar que a professora-cursista reconhece e apresenta o fundamento teórico para sua proposta de sala de aula, como descrito acima: Escolhi o texto de Luciana Andreia Ribeiro Leite, Era uma vez uma menina muito bonita, uma vez que vem ao encontro da história "Menina bonita do laço de fita". Assim, temos mais uma vez a marca da relação entre fundamento teórico e prática pedagógica. Percebendo o processo formativo da 


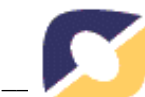

professora-cursista, observamos que a relação entre teoria e prática se constitui de forma específica e concreta. Aqui, o foco é o trabalho na sala de aula fundamentado por um estudo conceitual apresentado como proposta no curso PEAD/UFRGS.

Seguimos analisando outra experiência formadora da docência, no âmbito da relação entre teoria e prática.

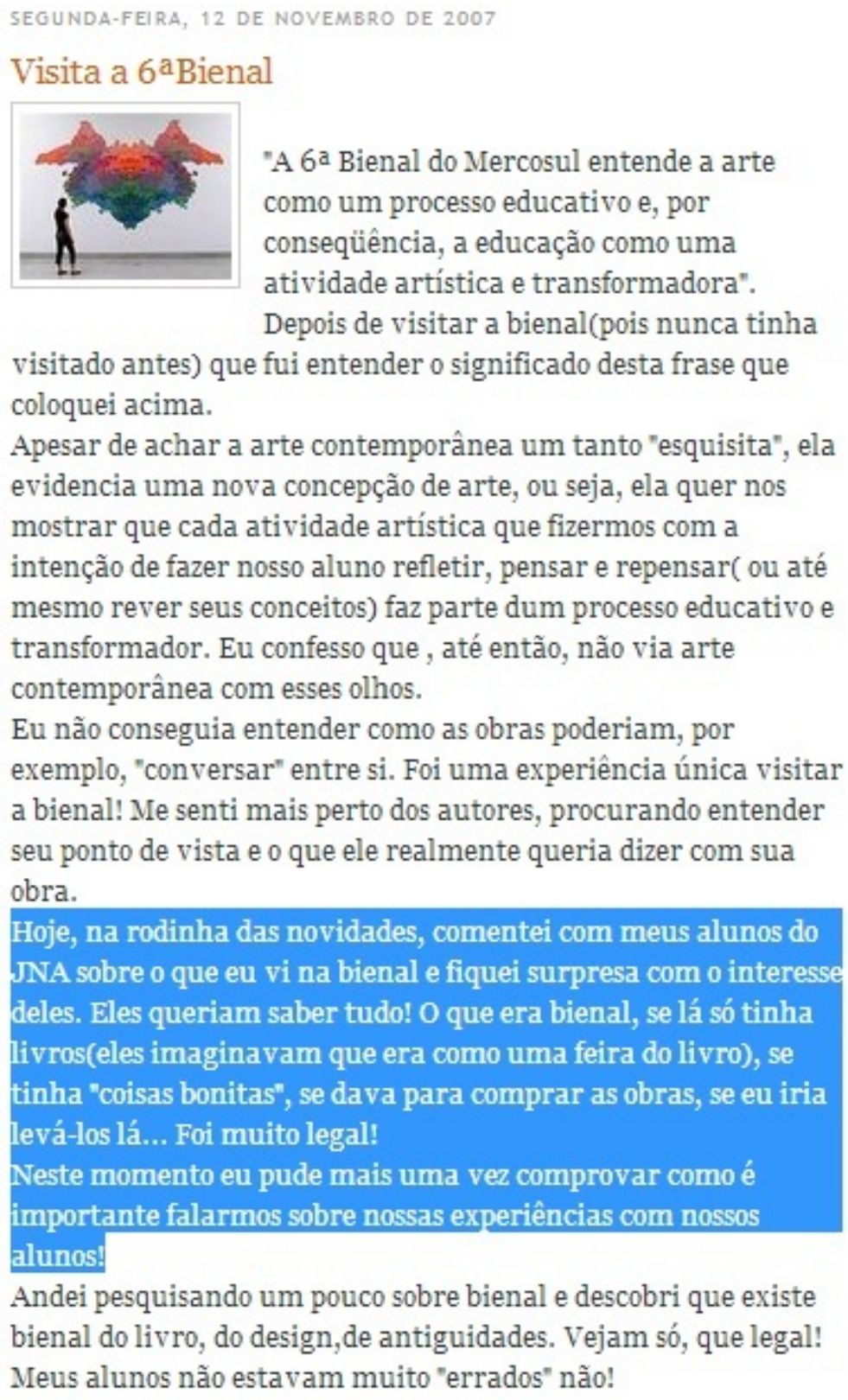

Figura 04 - Portfólio de Aprendizagens de IM, postagem de 12/11/2007.

A primeira postagem de destaque do Portfólio de Aprendizagens de IM reúne o relato da visita à $6^{a}$ Bienal do Mercosul, proposta pela interdisciplina “Artes Visuais”, e a repercussão desta visita no trabalho da professora-cursista com os alunos da Educação Infantil. Inicialmente, IM relata as aprendizagens consolidadas nessa visita: compreender a estrutura e sentido da Bienal, refinando seu olhar sobre a arte contemporânea. Essa vivência da professora-cursista, no entanto, se expande ao relatar para seus alunos a visita: Hoje, na rodinha das novidades, comentei com meus alunos do JNA sobre o que eu vi na bienal e fiquei surpresa com o interesse deles. Eles 
queriam saber tudo! [...]. Ao compartilhar com as crianças seus aprendizados na Bienal, IM conclui que é importante falarmos sobre nossas experiências com nossos alunos. Assim, temos a primeira marca na trajetória formativa da professora-cursista: aproximar a formação acadêmica do trabalho pedagógico desenvolvido em sala de aula, colocando o professor num lugar de aprendiz, que compartilha seu processo com os sujeitos envolvidos na formação.

Por fim, o destaque do professor-cursista ER, sintetiza a relação estabelecida como proposta do Portfólio de Aprendizagem, a partir da reflexão sobre o seu processo formativo.

\section{segunda-feira, 22 de outubro de 2007}

\section{Teoria X Prática}

Lendo as participações no Fórum, (estou procurando a citação) , foi postada a seguinte frase: "Como é bom estarmos discutindo as práticas educacionais, durante tanto tempo em outros cursos só se estudávam as teorias, muito bom podermos trocar idéias sobre o dia a dia da sala de aula. Eu não havia me dado conta ainda desse detalhe, pensando agora enquanto escrevo parece tão lógico, a diferenciação entre teoria e prática, mas enquanto estamos envolvidos com as leituras, com as discussões nos fóruns, as idéias começam a se fundir, e começamos a utilizar uma como aliada da outra. As duas passam a caminhar juntas

Talvez as duas estejam caminhando tão juntas pela forma como o curso está organizado, hora parece que estou estudando a teoria e colocando-a em prática, hora parece que estou fazendo um longo "estágio monitorado".

Muitas vezes ouve-se pelos corredores da educação: "Todas essas teorias são perda de tempo, quando se está na sala a coisa muda!". Com certeza que a coisa muda, na sala é onde você vive o seu papel de professor. Como no teatro onde o ator estuda o texto em casa, para mais tarde se expor ao seu público.

Antes, teoria era teoria, prática era prática, fico muito feliz com a proposta deste curso. Teoria e Prática andando juntas. Tão juntas que por vezes parecem uma coisa só. Conversando com colegas percebo que este é um pensamento comum, o curso está alcançando seus objetivos e crescendo a cada semestre.

Postado por — às 16:34 2 comentários: Links para esta postagem

Marcadores: educação, prática educacional, teoria educacional

Figura 05 - Portfólio de Aprendizagens de ER, postagem de 22/10/2007.

A Figura 05 destaca uma discussão já apresentada em outros casos analisados: Teoria X Prática. Na postagem, o professor-cursista reflete sobre a aproximação das teorias educacionais às experiências práticas na proposta do curso PEAD/UFRGS, de forma a não se perceber, em muitos momentos, a distinção entre uma e outra: [...] enquanto estamos envolvidos com as leituras, com as discussões nos fóruns, as ideias começam a se fundir, e começamos a utilizar uma como aliada da outra. As duas [teoria e prática] passam a caminhar juntas. Talvez as duas estejam caminhando tão juntas pela forma como o curso está organizado, hora parece que estou estudando a teoria e colocando-a em prática, hora parece que estou fazendo um longo "estágio monitorado". Segundo ER esse é um ponto fundamental da constituição do professor, que precisa tanto do estudo teórico quanto da experiência prática. Muitas professorascursistas expressaram em suas reflexões essa relação, e a postagem de ER traduz a ideia da proposta do curso, de "borrar" as fronteiras entre teoria e prática, proporcionando uma formação que vincula o pensar e o fazer no processo pedagógico. 
Dentre as trajetórias analisadas, no âmbito da relação entre teoria e prática observa-se que a expressão da relação entre o saber definido na formação e a possibilidade de "aplicação" em sua prática pedagógica foi fundamental e decisiva nas experiências formadoras. Todos os professores-cursistas mencionam, em algum momento da formação, o vínculo entre o saber e o saber-fazer: seja num relato de experiência concreta, seja no vislumbre de uma possibilidade de realização de proposta pedagógica. Diante da ideia de que a proposta do curso PEAD/UFRGS foi, também, transformar os conhecimentos científicos em prática pedagógica, percebemos que um objetivo central da formação é consolidado. Considera-se evidente falar da relação teoria e prática no âmbito da formação. No entanto, nas experiências descritas, essa relação expressou-se de forma consistente e vinculada a uma reflexão que contempla diversos enfoques: a relação que RW expressa, no início do curso de que os estudos no curso se relacionam à sua realidade educacional; a qualificação do embasamento teórico de SB, através do fundamento teórico desenhado em sua trajetória formativa; as relações estabelecidas por MB no momento do estágio curricular, de colocar em prática o que aprendeu no curso; a concepção de planejamento pedagógico definida por IM, em que teoria e prática se relacionam; até a síntese de ER: teoria e prática andando juntas, [...] que por vezes parecem uma coisa só.

Essa relação recupera o sentido delimitado por Josso acerca da definição de teoria e prática:

Teoria e prática são duas ordens de realidade, uma pertence ao campo da linguagem, do pensar, o outro ao do fazer, do sentir. Essas duas ordens se engendram, são a construção da forma uma da outra, elas se querem em correspondência, mesmo quando estão em dissonância. De uma certa maneira, esses dois polos se ameaçam, se desafiam. A teoria é a fôrma, a confecção, a receita, a explicação, a ordem, o geral; a prática é o singular, o imaginário, o sentido, o inesperado, o caos, o único. [...] Que ninguém se iluda: existe uma parte de prático e de teórico em cada um de nós [...]. (JOSSO, 2010, p. 82-83)

Estabelecer relação entre teoria e prática, nos itinerários de experiências individuais significa consolidar a experiência formadora, no sentido de aproximar o conhecimento ao saber-fazer. A reflexão a respeito dessa ação indica uma marca constituidora das experiências formadoras da docência: a recuperação do sentido da formação, como a integração do saber-fazer aos conhecimentos.

\section{Conclusões}

Como conclusões, compreendemos que as experiências formadoras relacionam-se necessariamente com o mundo da vida cotidiana de cada professora-cursista, ultrapassando as fronteiras da universidade e da escola. Além disso, as recordaçõesreferência apresentadas compuseram um rol de experiências formadoras destacadas para estes sujeitos. A relação entre teoria e prática consolidou a experiência formadora relaciona à aproximação do conhecimento ao saber-fazer, presente nas reflexões das professoras-cursistas.

No curso PEAD/UFRGS, ao qual acompanhamos desde o seu início até sua conclusão, esse desafio foi levado em consideração ao longo das propostas curriculares. Tratava-se de observar, cotidianamente, que os sujeitos envolvidos nessa formação (mesmo que inicial) são profissionais experientes, que trazem seus saberes e suas "verdades" a respeito da profissão, dos alunos e de como estes aprendem. 
O desafio parece ainda maior, pois além de ocorrer na modalidade a distância, a proposta curricular voltou-se para o interior da escola, para as suas práticas cotidianas e propôs o exercício da reflexão acerca da própria prática dos professores. Reconhecemos que no cotidiano da escola, muitas vezes esses docentes não encontram oportunidade para (re) pensar sua prática docente enquanto atuam.

Ter consciência da docência como uma profissão interativa, como ressaltam Tardif \& Lessard (2008), que lida, ao mesmo tempo “com” e "sobre” outros seres humanos e todas as implicações decorrentes dessa característica do trabalho docente também deve ser foco na formação de professores em exercício. A ideia de que o professor é um leitor de situações (TARDIF; LESSARD, 2008, p. 250) demanda a necessidade de construção de diversos sentidos sobre sua prática e sobre as distintas tramas que surgem na sala de aula.

Uma formação consistente, reflexiva, que aprofunde as tramas interacionais da sala de aula, como denominam Tardif e Lessard (2008), pode ser considerada uma alternativa para a formação de professores em exercício. Assim, observamos que esse desafio, não somente na formação na modalidade a distância, mas no cotidiano da escola em geral, deve ser objeto constante de problematização.

Oportunizar reflexões que estabeleçam relações com fatos e vivências do cotidiano que extrapolem a formação acadêmica é um imperativo na proposição de cursos de formação de professores. O processo de pensar a respeito de sua trajetória, refletindo sobre o seu processo deve ser estabelecido como meta para que a formação de professores tenha sentido em relação à realidade educacional e ao mundo da vida dos professores. Nesse sentido, reiteramos a ideia de Josso (2004, p.144), de que é possível articular pesquisa e formação como uma das formas possíveis de inovação pedagógica. O desafio, a partir de agora, é pensar possibilidades de articular a pesquisa-formação como proposta de formação de professores, a partir da experiência analisada em relação ao curso PEAD/UFRGS. Nesse sentido, defendamos a importância de assumirmos a experiência formadora como possibilidade de qualificar a formação de professores.

\section{Referências bibliográficas}

CHARLOT, Bernard. Da relação com o saber: elementos para uma teoria. Porto Alegre, Artmed, 2008.

GUIA DO PROFESSOR. Curso de Licenciatura em Pedagogia a Distância. Porto Alegre, julho de 2006.

JOSSO, Marie-Christine. Experiências de vida e formação. São Paulo: Cortez, 2004.

JOSSO, Marie-Christine. Caminhar para si. Porto Alegre: EDIPUCRS, 2010

LEMOS, André. Cibercultura, tecnologia e vida social na cultura contemporânea. Porto Alegre: Sulina, 2008.

NEVADO, R.; CARVAlHO, M.J. \& MENEZES, C. (Org.). Aprendizagem em rede na educação a distância: estudos e recursos para a formção de professores. Porto Alegre: Ricardo Lenz, 2007.

RODRIGUES, Cláudia M. Cruz (Coord.). Relatório de avaliação: Curso de Graduação Licenciatura em Pedagogia a Distância. Universidade Federal do Rio Grande do Sul. Departamento de Engenharia de Produção e Transportes, 2011. 
SANTOS, Maria José A. Estudo de caso sobre os usos do tempo entre alunas em curso de Pedagogia na modalidade a distância. 2010. 61f. (Dissertação de Mestrado).

SCHWARTZ, Yves. Trabalho e Saber. Trabalho \& Educação, vol.12, n.1 - jan-jun, 2003, p. 21-34. p. 35-48.

A experiência é formadora? Educação \& Realidade, vol.35, n.1, jan-abr, 2010,

TARDIF, Maurice. Saberes docentes e formação profissional. Petrópolis: Vozes, 2007.

TARDIF, Maurice; LESSARD, Claude. O trabalho docente: elementos para uma teoria da docência como profissão de interações humanas. Petrópolis: Vozes, 2008. 